\title{
A Multilevel Voltage-Source Converter System with Balanced DC Voltages*
}

\author{
Fang Zheng Peng \\ University of Tennessee, Knoxville \\ ORNL, P.O. Box 2003, K-1220 \\ Oak Ridge, Tennessee 37831-7280 \\ Tel: 615-576-7261 Fax: 576-0279 \\ email: pengfz@ornl.gov
}

\author{
Jih-Sheng Lai, John McKeever and \\ James VanCoevering \\ Oak Ridge National Laboratory ${ }^{* *}$ \\ P.O. Box 2003, Bldg. K-1220 \\ Oak Ridge, Tennessee 37831-7280 \\ Tel: $615-576-6223$
}

\begin{abstract}
In this paper, a multilevel voltage-source converter system is proposed for high-voltage, high-power applications such as large induction motor drives, back-to-back interconnected power systems, and electrical traction drives. Multilevel voltage-source converters have a voltage unbalance problem in the dc capacitors. The problem may be solved by use of additional voltage regulators or separate dc sources. However, these solutions are found not to be practicable for most applications. The proposed converter system can solve the voltage unbalance problem of the conventional multilevel voltage-source converters, without using any additional voltage balance circuits or separate voltage sources. Mechanism of the voltage unbalance problem is analyzed theoretically in this paper. The validity of the new converter system is demonstrated by simulation and experiment.
\end{abstract}

The applicable topics category is

5. Utility Interface Issues and HighPower Applications, or

3. Power Converters for Drive Applications.

** Prepared by the Oak Ridge National Laboratory, Oak Ridge, Tennessee 37831-7280, managed by Martin Marietta Energy Systems, Inc. for the U. S. Department of Energy under contract DE-AC05-84OR21400.

The submitted manuscript has been authored by a contractor of the U. S. Government under contract No. DE-AC0584OR21400. Accordingly, the U. S. Government retains a nonexclusive, royalty-free license to publish or reproduce the published form of this contribution, or allow others to do so, for U. S. Government purposes. 


\section{DISCLAIMER}

Portions of this document may be illegible in electronic image products. Images are produced from the best available original document. 


\section{A Multilevel Voltage-Source Converter System with Balanced DC Voltages}

\section{Digest}

In recent years, the volt-ampere (VA) ratings of voltage-source converters using gate-turnoff thyristors (GTOs) have reached several tens of mega-VA in many areas such as industrial applications and high voltage power system applications[1 8]. However, the development of large VA rated converters with low harmonic distortion and fast dynamic response has been limited by the use of bulky transformers for multiple connections, the device ratings, and problems of series connections of devices[5]. On the other hand, a multilevel voltage-source converter has been attracting many researchers[9 11], as it has the following features compared with a conventional 2level pulse-width-modulation (PWM) converter:

(1) It is much more suitable to high voltage, large VA rated applications. The efficiency is much higher, can be more than $99 \%$.

(2) It generates an M-step staircase waveform of output voltage with the line frequency switching and without converter transformers for an M-level converter (see Figs. 1 and 2), thus reaching almost pure sinusoidal output voltage by increasing the number of levels.

(3) Since the multilevel converter itself consists of series connection of switching devices and each device is clamped to the dc capacitors through the diodes, it does not require special considerations to balance voltages of the switching devices.

(4) Electromagnetic interference (EMI) level is much lower because $d v / d t$ at switching is one (M-1)th of that of the conventional 2-level converters.

So far, however, multilevel converters have not been successfully implemented for motor drives, power system applications, etc.[5, 10,11], except for static var compensation[12]. Since series capacitors are used to divide the dc voltage, multilevel converters have a voltage unbalance problem between the dc capacitors. The problem may be solved by separate dc sources[5, 9] or by voltage regulators for each level[10]. The requirement of separate dc sources or voltage regulators is not suitable for many applications because additional isolation transformers and switching devices are necessary.

In this paper, a multilevel voltage source converter system is proposed. The new converter system consists of a multilevel rectifier and a multilevel inverter, which can solve the voltage unbalance problem. Since the rectifier and the inverter are completely symmetrical, the converter system can generate low distortion of voltage and current both on the ac source side and on the load side. A control method is proposed. Some simulated and experimental results are shown to demonstrate the validity of the new converter system. 


\section{Converter Structures and Operation Principle}

Fig. 1 shows a general structure of M-level converters. Fig. 2 shows the output phase voltage. Obviously, the converter can reach high voltage, large VA rating, and harmonic reduction by itself, unlike conventional transformer-based multiple converters. The $\mathrm{M}$-level converter generates $\mathrm{M}$ steps of phase voltage, (2M-1) steps of line-to-line voltage over a half cycle. However, since capacitors are used to generate voltage levels from $V_{2}$ to $V_{(M-1)}$, voltage across each capacitor cannot be unbalanced in principle. The mechanism of voltage unbalance will be explained in detail in the final paper. This capacitor voltage unbalance issue has hindered applications of the multilevel voltage source converters.

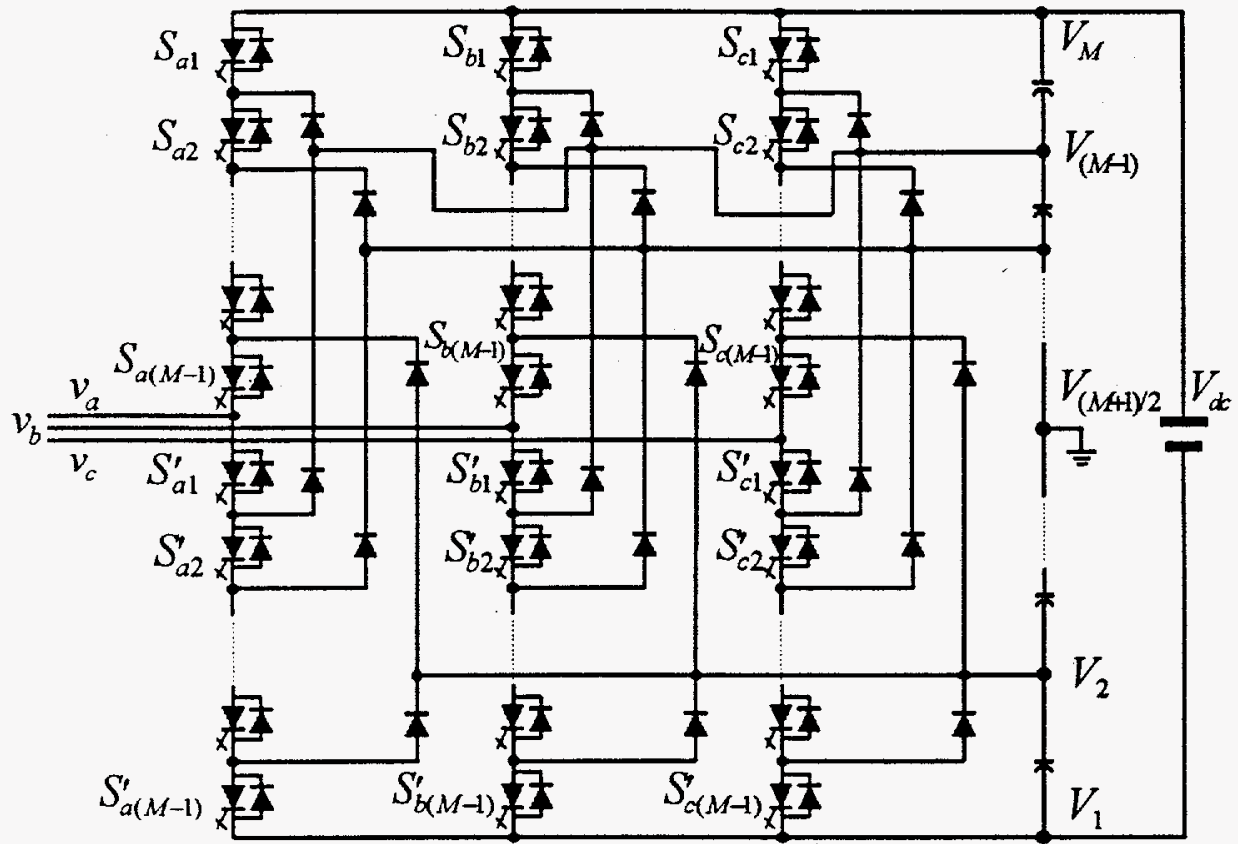

Fig.1 Structure of an M-level voltage source converter.

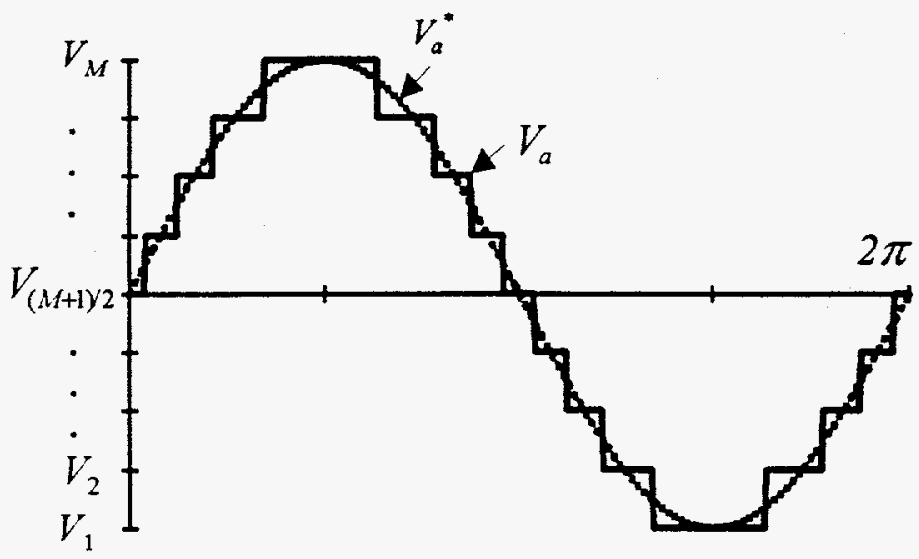

Fig.2 Output waveform of phase voltage. 
Fig. 3 shows the structure of the proposed converter system, which consists of two completely symmetrical $\mathrm{M}$-level converters (here, $\mathrm{M}=5$ ), one on the ac source side for ac-to-dc conversion and the other on the load side for dc-to-ac inversion. The key point of this system is that the corresponding internal voltage levels of the two converters, $V_{2}$ through $V_{4}$, are connected together, respectively. These connections enable voltage balance of capacitors. The principle will be illustrated in detail in the final paper.

Fig.4 shows the control block diagram for the ac/dc converter, where $V_{d c}{ }^{*}$ is the reference of the dc voltage, $V_{C}^{*}$ and $\alpha_{C}$ are the amplitude reference and phase reference of converter output voltage, respectively, and $I_{S Q}{ }^{*}$ is the reference of reactive current of source current $i_{S}$. The reactive power can be controlled in this system. For example, choosing $I_{S Q}^{*}=0$ will result in unity power factor. The dc link voltage is controlled through changing the phase difference, $\alpha_{C}$, between $V_{S}$ and $V_{C}$. The switching pattern table in the diagram stores the optimum switching angles for harmonics minimization.

Fig. 5 shows some simulation results of Figs. 3 and 4. Fig.5(a) shows dc voltages. It is obvious that the capacitor voltages are well balanced. Fig.5(b) shows the source voltage and source current with a unity power factor and low distortion. Fig.5(c) shows the voltage and current of the motor. The detailed results and some theoretical analysis will be included in the final paper.

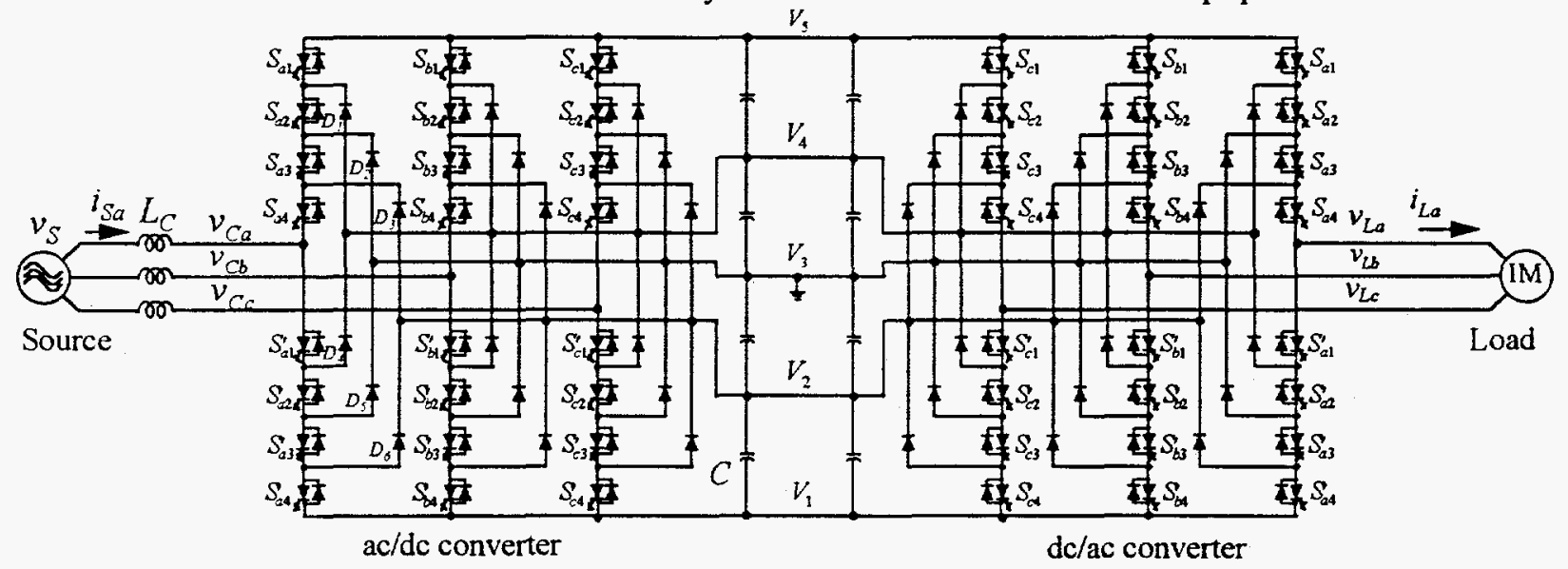

Fig.3 A structure of the proposed M-level converter system ( $M=5)$.

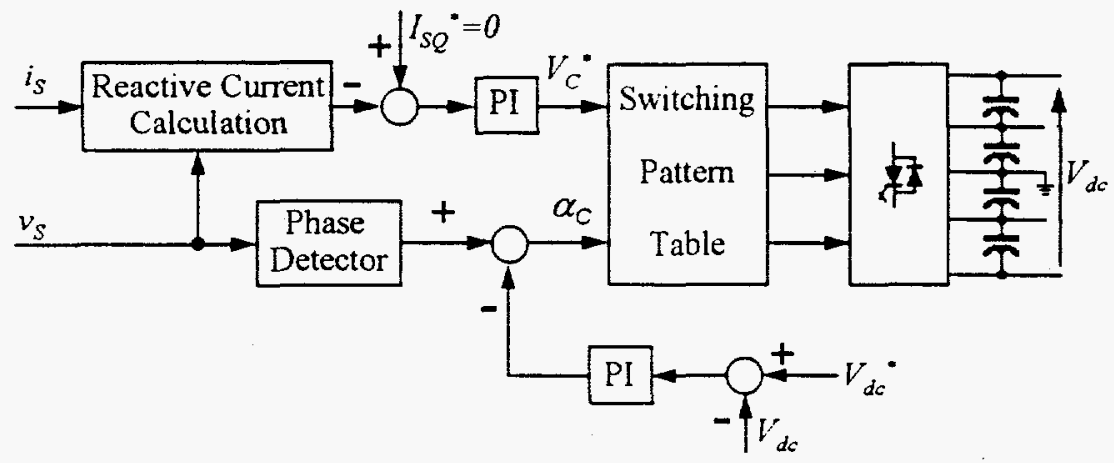

Fig. 4 Control scheme of ac/dc multilevel converter. 


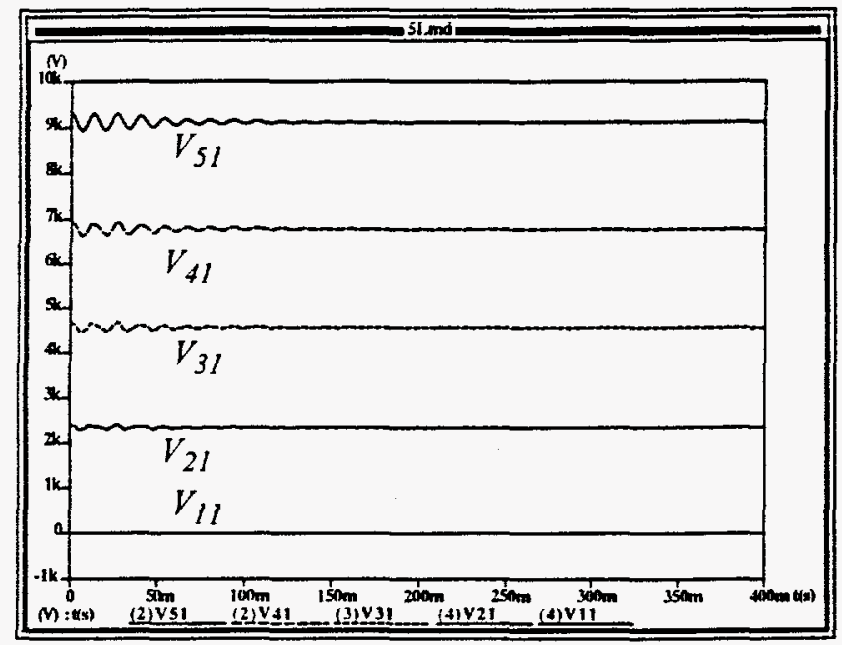

Fig.5(a) Voltages of the dc links, i.e., the voltages of $V_{5}$ to $V_{1}$ referring to $V_{1}$.

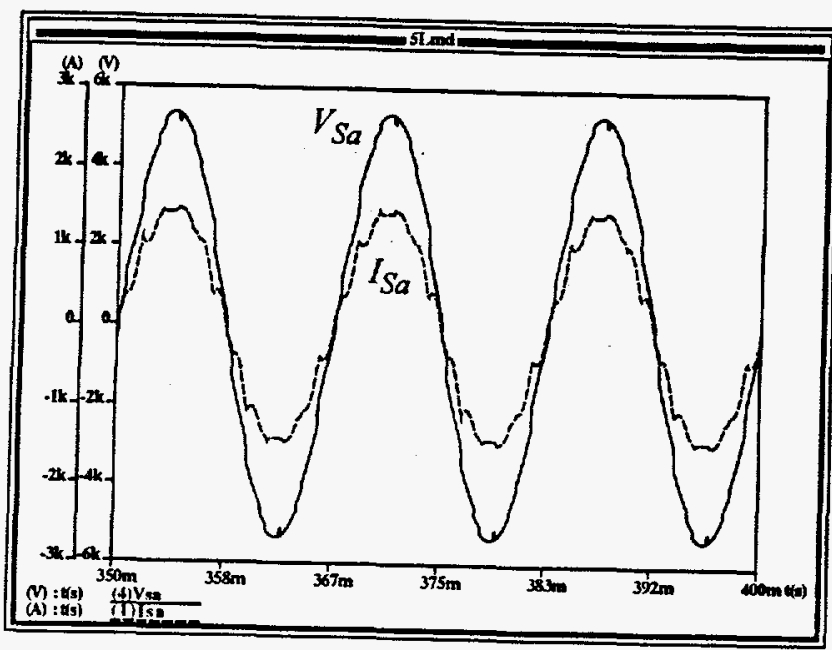

Fig.5(b) Source voltage and source current.

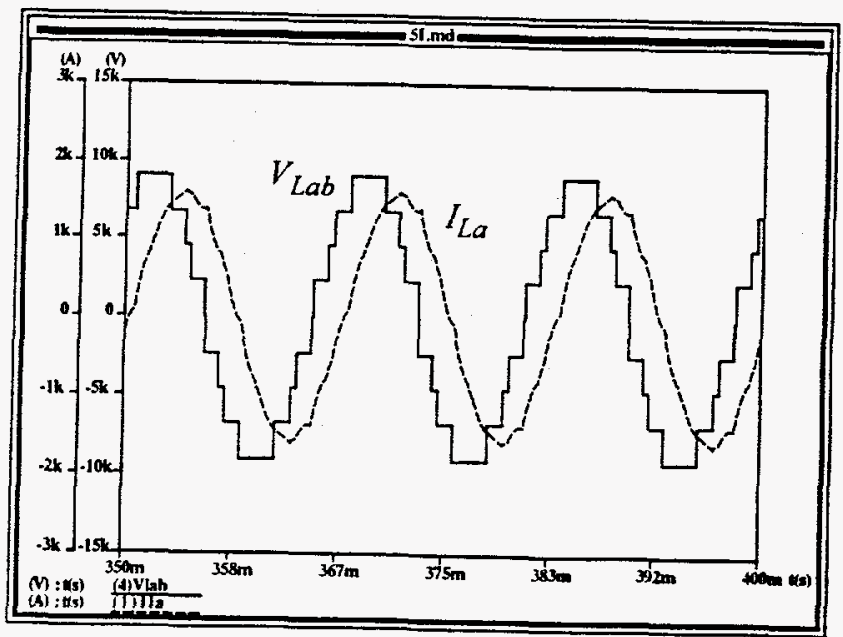

Fig.5(c) Voltage and current of motor. 


\section{References}

[1] L. H. Walker, "10MW GTO converter for battery peaking service," IEEE/IAS Annual Meeting, pp.850-858, 1988.

[2] J. Holtz and S. F. Salama, "Megawatt GTO inverter with three-level PWM control and regenerative snubber circuits," IEEE/PESC, Kyoto/Japan, pp.1263-1271, 1988.

[3] C. Schauder, et al., "Development of a $\pm 100 \mathrm{MVar}$ static condenser for voltage control of transmission systems," IEEE/PES Summer Power Meeting, Paper No. 94 SM 479-6 PWRD, 1994.

[4] T. Sukegawa, K. Kamiyama, and et al., "A multiple PWM GTO line-side converter for unity power factor and reduced harmonics," IEEE/IAS Annual Meeting, pp.279-284, 1991.

[5] R. W. Menzies, P. Steimer, and J. K. Steinke, "Five level GTO inverters for large induction motor drives," IEEE/IAS Annual Meeting, pp.595-601, 1993.

[6] N. Seki, et al., "A test method suitable for high power GTO converter," IEE Japan IAS '92 pp.E/184-189, 1992.

[7] H. Miki, and et al., "New AC traction drive system with transistor VVVF inverter," IEEE/IAS Annual Meeting, pp.291-297, 1991.

[8] O. Kawabata and K. Oshitani, "Development of the high voltage power switching circuit with GTOs operated by new gate-drive system," IEEE/IAS Annual Meeting, pp.1003-1008, 1993.

[9] A. Campagna, et al., "A new generalized multilevel three-phase structure controlled by PWM," Proc. of Fourth European Conf. on Power Electronics and Applications, pp.III/235-240, 1991.

[10] Nam S. Choi, Jung G. Cho and Gyu H. Cho, "A general circuit topology of multilevel inverter," IEEE/PESC, pp.96-103, 1991.

[11] J. S. Lai and F. Z. Peng, "Power converter options for power system compatible mass transit systems," PCIM/Power Quality \& Mass Transit 194 Conference, Ventura California, Sept. 1994.

[12] H. Ide, F. Z. Peng and T. Fukao, "An SVG using multilevel inverter," IEE Japan, SPC-93-71, 1993.(in Japanese)

\section{DISCLAIMER}

This report was prepared as an account of work sponsored by an agency of the United States Government. Neither the United States Government nor any agency thereof, nor any of their employees, makes any warranty, express or implied, or assumes any legal liability or responsibility for the accuracy, completeness, or usefulness of any information, apparatus, product, or process disclosed, or represents that its use would not infringe privately owned rights. Reference herein to any specific commercial product, process, or service by trade name, trademark, manufacturer, or otherwise does not necessarily constitute or imply its endorsement, recommendation, or favoring by the United States Government or any agency thereof. The views and opinions of authors expressed herein do not necessarily state or reflect those of the United States Government or any agency thereof. 